\title{
Perbaikan Proses di Dalam Gudang Mengunakan Metode DMAIC Pada PT. Dakota Logistik Indonesia
}

\author{
M. Tirtana Siregar \\ Politeknik APP Jakarta, Jakarta Selatan, Indonesia \\ email: tirtana.mts@gmail.com \\ Tita Mutiara \\ Politeknik APP Jakarta, Jakarta Selatan, Indonesia \\ email: tirtana.mts@gmail.com
}

\begin{abstract}
This paper aims to find out and analyze the damage to medicinal and medical devices stored in the warehouse of PT. Dakota Logistics Indonesia. The problem found during January-March 2018 is the number of goods claims in the warehouse of PT. Dakota Logistics Indonesia. Data needed for this paper are claims for drug and medical equipment claims, types of claim items during January-March 2018 and goods claim cost data during January-March 2018. While the proposed improvements use the DMAIC method. Based on the DMAIC method the cause of the most claims is damage to broken goods on drugs and medical devices PT. I. While the proposed improvements are work instructions on the process of unloading and loading on the process in the warehouse of PT. Dakota Logistik Indonesia as well as adding item information columns to customer purchase orders.
\end{abstract}

Keywords: DMAIC, claim, warehouse

\begin{abstract}
Abstrak
Tulisan ini bertujuan untuk mengetahui dan menganalisis kerusakan barang obat dan alat kesehatan yang disimpan di gudang PT. Dakota Logistik Indonesia. Permasalahan yang ditemukan selama Januari-Maret 2018 adalah banyaknya klaim barang dalam gudang PT. Dakota Logistik Indonesia. Data yang dibutuhkan untuk tulisan ini adalah data klaim barang obat dan alat kesehatan, jenis klaim barang selama Januari-Maret 2018 dan data biaya klaim barang selama Januari-Maret 2018. Sedangkan usulan perbaikannya menggunakan metode DMAIC. Berdasarkan metode DMAIC penyebab klaim terbanyak adalah kerusakan barang pecah pada obat dan alat kesehatan PT. I. Sedangkan usulan perbaikannya adalah instruksi kerja pada proses unloading dan loading pada proses di dalam gudang PT. Dakota Logistik Indonesia serta penambahan kolom informasi barang pada purchase order customer.
\end{abstract}

Kata kunci: DMAIC, Klaim Barang, Gudang. 


\section{PENDAHULUAN}

Berkembangnya era globalisasi meliputi era digital dimana transaksi jual beli dilakukan secara online atau biasa disebut e-commerce. Seiring dengan berkembangnya era e-commerce di Indonesia, perusahaan jasa ekspedisi pun ikut berkembang pesat untuk mendukung pengiriman barang-barang konsumen $e$ commerce. Berkembangnya jasa ekspedisi di Indonesia, maka perusahaan-perusahaan jasa ekspedisi tersebut berusaha memberikan layanan yang terbaik. Bentuk pelayanan tersebut diantaranya jasa layanan penjemputan barang ke rumah customer, tracking barang, one day service, dan sebagainya.

Jenis klaim yang terjadi pada proses di dalam gudang PT. Dakota Logistik Indonesia diantaranya pecah untuk produk obat cair maupun obat tablet, packaging robek untuk produk packaging karton, hilang, penyok untuk produk berbentuk drum dan tercemar untuk produk karton yang terkontaminasi air atau zat cair lainnya. Pada masalah klaim tersebut yang harus bertanggung jawab atas klaim barang adalah pihak admin marketing serta pihak operasional yang menangani barang tersebut.

Selama Januari - Maret 2018 perusahaan ini menerima klaim barang dalam proses di gudang khususnya dari customer perusahaan obat dan alat kesehatan. Contoh produk obat dan alat kesehatan yang packaging nya robek tidak diterima oleh customer dan diminta untuk penggantian packaging karena dikhawatirkan kemungkinan masuknya hama dan hal-hal yang tidak diinginkan yang menyebabkan isi barang rusak atau terkontaminasi. Klaim ini dikarenakan perusahaan manufaktur obat dan alat kesehatan menginginkan barangnya zero defect atau tidak menerima barang yang cacat. Perusahaan manufaktur obat dan alat kesehatan yang menjadi customer tetap dan menerapkan zero defect PT. Dakota Logistik Indonesia adalah PT. I, PT. M dan PT. CS. Berikut adalah total klaim barang dari perusahaan obat dan alat kesehatan.

\section{Metode DMAIC (Define-Measure-} Analyze-Improve-Control) merupakan pendekatan untuk meningkatkan kualitas suatu proses atau produk sehingga dapat mengurangi atau menghilangkan kecacatan yang dapat merugikan perusahaan. Berdasarkan masalah yang sudah dijabarkan di paragraf sebelumnya masalah yang dihadapi oleh PT. Dakota Logistik Indonesia adalah biaya klaim barang yang meningkat setiap bulannya. Dengan menerapkan metode DMAIC diharapkan dapat mengurangi kecacatan barang di PT. Dakota 
Logistik Indonesia sehingga dapat mengurangi biaya klaim.

\section{TELAAH LITERATUR}

Menurut Gaspersz 2007, DMAIC adalah suatu metode perbaikan kualitas dengan cara melihat proses yang sudah ada dan melakukan perbaikan atas masalahmasalah yang muncul. DMAIC dapat digunakan untuk menghilangkan langkahlangkah proses yang tidak produktif. Terdapat 5 tahapan dalam penyelesaian masalah yang dikenal dengan Metode DMAIC. Berikut ini adalah 5 Tahapan DMAIC :

1. Define - terdiri atas pengamatan awal yang dilakukan untuk mengetahui profil perusahaan, bahan baku yang digunakan, alur proses yang ada pada perusahaan, menentukan karakteristik kualitas dan menentukan kriteria kecacatan. Pada tahap define akan menentukan produk atau jasa yang pelanggan butuhkan dan apa yang diharapkan pelanggan dari segi produk dan jasa. Pada tahap ini ada beberapa hal yang perlu dilakukan yaitu:

a. Mengidentifikasi kebutuhan dan keinginan konsumen, baik dari desain maupun kinerja aktual dari suatu produk layanan perusahaan. b. Mendefinisikan dan membatasi lingkup akar permasalahan.

c. Mengembangkan sasaran perbaikan, indikator-indikator kinerja sasaran perbaikan dan pengukurannya.

2. Measure - setelah tahapan define dilakukan, langkah selanjutnya adalah pengumpulan data, memvalidasi permasalahan dan mengukur/menganalisis permasalahan terkait data yang ada. Langkah-langkah tahapan measure adalah:

a. Menentukan jenis dan sumber data yang akan dikumpulkan.

b. Merancang metode pengumpulan data.

c. Melakukan pengumpulan data dengan cara observasi, wawancara, kuesioner untuk data primer atau pengumpulan data yang diambil dari sistem database dan laporan untuk data sekunder.

3. Analyze - data yang telah dikumpulkan akan dianalisis dengan cara membandingkan antara kinerja kualitas aktual saat ini dengan sasaran kinerja kualitas yang diinginkan untuk mengetahui dan menganalisa jenis kecacatan yang sering terjadi dari yang paling sering terjadi sampai yang paling jarang terjadi. Dari analisis data ini dapat dilakukan identifikasi masalah yang selanjutnya dapat dilakukan serangkaian pengembangan beberapa alternatif solusi perbaikan kualitas. Pada tahap ini dilakukan 
identifikasi dan verifikasi data sehingga perumusan masalah dan identifikasi akar masalah dapat dilakukan dengan lebih tepat dan tajam.

4. Improve - pada tahap ini dilakukan pengembangan dan implementasi solusi perbaikan atas akar masalah yang terjadi serta mendiskusikan ide-ide kreatif untuk mengatasi masalah. Ide-ide yang sudah diputuskan selanjutnya diimplementasikan pada proses kerja. Pada tahap ini dilakukan:

a. Mengembangkan dan mengevaluasi akar penyebab masalah.

b. Mengembangkan alternatif solusi perbaikan.

c. Menetapkan secara jelas penugasan tim yang bertanggung jawab atas perbaikan kualitas.

d. Mengimplementasikan perbaikan.

e. Memvalidasi perbaikan dengan kebutuhan dan keinginan konsumen.

5. Control - pada tahap ini dilakukan pengendalian atas hasil perbaikan agar proses berjalan lancar serta mencegah terulangnya kesalahan masa lalu. Pada tahap ini kita juga harus membuat semacam metriks sebagai alat untuk me-monitoring dan mengoreksi hasil perbaikan apabila sudah mulai menurun atau untuk melakukan perbaikan lagi. Pada tahap control ini dilakukan: a. Periksa dampak perbaikan dalam jangka panjang.

b. Menyusun rencana perbaikan rencana berkelanjutan.

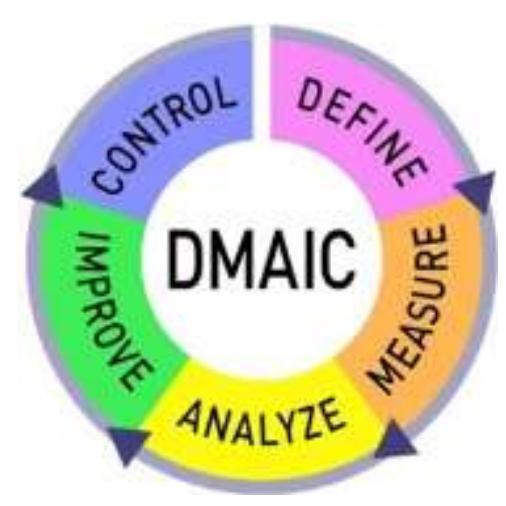

Gambar .1

Gambar Siklus DMAIC

\section{METODE PENELITIAN}

\section{Teknik Pemecahan Masalah}

Penelitian ini dilakukan di PT. Dakota Logistik Indonesia. Pendekatan yang digunakan dalam penulisan tulisan ini adalah pendekatan kualitatif dan analisis kegiatan di lapangan tepatnya pada bagian operasional.

\section{Teknik Pengumpulan Data}

Sumber data yang digunakan dalam penulisan tugas akhir ini adalah sebagai berikut.

\section{Data Primer}

Data primer adalah data yang diperoleh atau dikumpulkan secara langsung dari sumber datanya. Teknik yang digunakan untuk 
mengumpulkan data primer adalah sebagai berikut.

\section{a. Observasi}

Pada teknik observasi melakukan proses pengamatan dan pencatatan secara sistematis mengenai proses penyimpanan barang di gudang PT. Dakota Logistik Indonesia. Teknik pengumpulan data ini dapat melihat langsung proses penyimpanan di gudang dan kondisi barang di gudang.

b. Wawancara

Pada teknik wawancara akan dilakukan tanya jawab dengan divisi yang terkait untuk memperoleh informasi yang terkait dengan masalah yang diambil oleh penulis

\section{Data Sekunder}

Data sekunder adalah data yang diperoleh atau dikumpulkan secara tidak langsung melalui media perantara (diperoleh dan dicatat oleh orang lain). Data sekunder umumnya berupa bukti, catatan atau laporan historis yang telah tersusun dalam arsip yang dipublikasikan maupun tidak dipublikasikan. Data-data tersebut meliputi:

a. Data biaya klaim periode Januari - Maret 2018.

b. Data kerusakan barang obat dan alat kesehatan periode Januari - Maret 2018. c. Data lamanya bekerja karyawan divisi operasional tahun 2018.

\section{Metode Analisis}

Dari data yang sudah diperoleh, maka perlu mengolahnya agar permasalahan dapat diselesaikan dengan baik, dengan melakukan tahap-tahap sebagai berikut:

1) Pengolahan data

Hasil dari penyajian data akan diolah ke dalam metode DMAIC dengan tahapan berikut:

\section{a. Define}

Pada fase ini dilakukan pengamatan awal yang dilakukan dengan menentukan perusahaan manufaktur obat dan alat kesehatan yang memiliki klaim kerusakan barang tertinggi menggunakan data perbandingan klaim kerusakan barang antar perusahaan barang obat dan alat kesehatan. Data kerusakan tersebut didapatkan dari berita acara perusahaan.

\section{b. Measure}

Data yang dibutuhkan dikumpulkan dan dihitung. Setelah diketahui jenis barang yang akan di jadikan fokus perbaikan selanjutnya menghitung jenis kerusakan yang akan dijadikan fokus perbaikan dengan menggunakan diagram pareto. Pada diagram pareto akan membandingkan jenis kerusakan yang paling banyak terjadi dengan biaya yang 
harus dikeluarkan. Kerusakan dengan biaya tertinggi akan dijadikan sebagai fokus perbaikan. Diagram pareto dibuat menggunakan aplikasi Minitab 17.

c. Analyze

Tahap ini menganalisa penyebab jenis kecacatan yang telah ditentukan di tahap measure. Selanjutnya dilakukan brainstorming untuk mengetahui penyebab masalah. Proses brainstorming dilakukan dengan divisi terkait yaitu divisi operasional. Setelah didapatkan hasil brainstorming selanjutnya di buat diagram sebab akibat (fishbone) menggunakan pendekatan $5 \mathrm{M}+1 \mathrm{E}$. Pada diagram sebab akibat dipilih faktor penyebab yang paling berpengaruh terhadap kecacatan tersebut.

\section{d. Improve}

Pada tahap ini solusi dan ide kreatif dibuat dan diputuskan untuk perbaikan proses. Setelah mengetahui faktor penyebab terjadinya kerusakan selanjutnya dibuat rancangan perbaikan.

\section{e. Control}

Pada tahap ini dibuat alat untuk memonitoring dan mengukur usulan perbaikan pada tahap improve. Alat ini digunakan untuk mengetahui dan menganalisis efektivitas usulan perbaikan pada saat perusahaan telah melakukan implementasi.

\section{2) Usulan Perbaikan}

Dari hasil pembahasan akan dilakukan usulan perbaikan bagi perusahaan berupa proses perbaikan yang dapat dilakukan secara terus menerus. Usulan perbaikan dibuat berdasarkan tahap metode DMAIC.

Bagian ini memuat rancangan penelitian atau desain penelitian, sasaran dan target penelitian (populasi dan sampel), teknik pengumpulan data, model penelitian, dan teknik analisis.

\section{HASIL DAN PEMBAHASAN}

\section{Tahap Define}

Tahap ini merupakan tahap awal dalam melakukan metode DMAIC. Pada tahap define ditentukan lingkup masalahnya. Berdasarkan wawancara dengan kepala divisi marketing diketahui bahwa perusahaan yang sering melakukan klaim barang selama bulan Januari-Maret 2018 adalah perusahaan manufaktur obat dan alat kesehatan dengan total klaim sebagai berikut. 
Tabel 1.

Total Klaim barang Obat dan Alat

Kesehatan Januari-Maret 2018

\begin{tabular}{|c|l|c|c|c|c|c|c|c|}
\hline \multirow{2}{*}{ No } & \multirow{2}{*}{$\begin{array}{c}\text { Jenis } \\
\text { Kerusakan }\end{array}$} & \multicolumn{2}{|c|}{ PT. I } & \multicolumn{2}{c|}{ PT. M } & \multicolumn{2}{c|}{ PT. CS } & \multirow{2}{*}{ Torang } \\
Obat & $\begin{array}{c}\text { Alat } \\
\text { Kesehatan }\end{array}$ & $\begin{array}{c}\text { Barang } \\
\text { Obat }\end{array}$ & $\begin{array}{c}\text { Alat } \\
\text { Kesehatan }\end{array}$ & $\begin{array}{c}\text { Barang } \\
\text { Obat }\end{array}$ & $\begin{array}{c}\text { Alat } \\
\text { Kesehatan }\end{array}$ & \\
\hline 1 & Pecah & 60 & 22 & 34 & 12 & 7 & 3 & 138 \\
\hline 2 & $\begin{array}{l}\text { Penggantian } \\
\text { packaging }\end{array}$ & 15 & 15 & 24 & 18 & 9 & 6 & 87 \\
\hline 3 & Tercemar & 13 & 4 & 8 & 4 & 4 & 2 & 35 \\
\hline 4 & Hilang & 1 & 0 & 1 & 0 & 0 & 0 & 2 \\
\hline 5 & Drum penyok & 5 & 0 & 3 & 0 & 3 & 0 & 11 \\
\hline \multicolumn{2}{|c|}{ total } & 135 & & 104 & & 34 & 273 \\
\hline
\end{tabular}

Berdasarkan tabel diatas diketahui bahwa perusahaan yang memiliki jumlah klaim terbanyak selama Januari-Maret 2018 adalah PT. I dengan jenis klaim pecah, penggantian packaging (packaging robek), tercemar, drum penyok dan hilang. Maka dari itu, lingkup masalahnya adalah perusahaan yang memiliki klaim terbanyak adalah pada barang obat dan alat kesehatan PT. I.

Berdasarkan wawancara dengan Ka. Operasional dan admin marketing atau PIC yang memegang PT. I terdapat 5 CTQ (critical to quality) selama Januari-Maret 2018 yang dapat mengurangi pelayanan ke customer. 5 jenis klaim tersebut adalah pecah, penggantian packaging (packaging robek), tercemar, hilang dan drum penyok.
Tabel 2.

Jenis Klaim Selama Bulan Januari-Maret 2018

\begin{tabular}{|c|c|c|}
\hline No. & CTQ & Keterangan \\
\hline 1. & Pecah & $\begin{array}{l}\text { Packaging terbuat } \\
\text { dari kaca maupun } \\
\text { botol plastik. }\end{array}$ \\
\hline 2. & Tercemar & $\begin{array}{l}\text { Barang yang } \\
\text { terkontaminasi oleh } \\
\text { rembesan air dan } \\
\text { terkontaminasi isi } \\
\text { dari barang yang } \\
\text { pecah. Jenis } \\
\text { kerusakan ini harus } \\
\text { diganti keseluruhan. }\end{array}$ \\
\hline 3. & $\begin{array}{l}\text { Penggantian } \\
\text { packaging }\end{array}$ & $\begin{array}{l}\text { Penggantian } \\
\text { packaging adalah } \\
\text { packaging karton } \\
\text { yang hanya cacat } \\
\text { dibagian packaging } \\
\text { dan pada isinya } \\
\text { tidak ada } \\
\text { kerusakan. }\end{array}$ \\
\hline 4. & Hilang & $\begin{array}{l}\text { Barang yang wujud } \\
\text { fisiknya tidak ada } \\
\text { (di curi atau saat } \\
\text { penerimaan barang } \\
\text { ada tetapi saat di } \\
\text { loading tidak ada) }\end{array}$ \\
\hline 5. & Drum penyok & $\begin{array}{l}\text { Merupakan } \\
\text { packaging yang } \\
\text { berbentuk jerigen } \\
\text { kaleng maupun } \\
\text { plastik yang berisi } \\
\text { bahan B3 ataupun } \\
\text { bahan pembuat obat } \\
\text { berbentuk cair. }\end{array}$ \\
\hline
\end{tabular}

Sumber: Data Wawancara 2018

Tabel diatas merupakan CTQ (critical to quality) beserta penjelasan kriteria klaim selama bulan Januari-Maret 2018 dan dapat berubah sesuai dengan kerusakan yang terjadi pada periode tersebut. Pada perusahaan manufaktur obat 
dan alat kesehatan barang-barang yang dikirim tidak boleh ada yang cacat karena akan berpengaruh pada isi maupun informasi dari barang tersebut.

\section{Tahap Measure}

Tahap measure menunjukkan hasil dari data tingkat kecacatan yang terjadi pada proses penyimpanan barang. Aktivitas yang dilakukan pada tahap ini adalah pengambilan data kerusakan barang serta pengamatan langsung di lapangan. Sebelumnya pada tahap define ditentukan bahwa lingkup permasalahan klaim barang adalah pada barang dari perusahaan PT. I. Dengan menggunakan data kerusakan barang maka dapat dilakukan pembuatan diagram pareto untuk mengetahui permasalahan mana yang akan dijadikan prioritas perbaikan.

Gambar 2.

Diagram Pareto

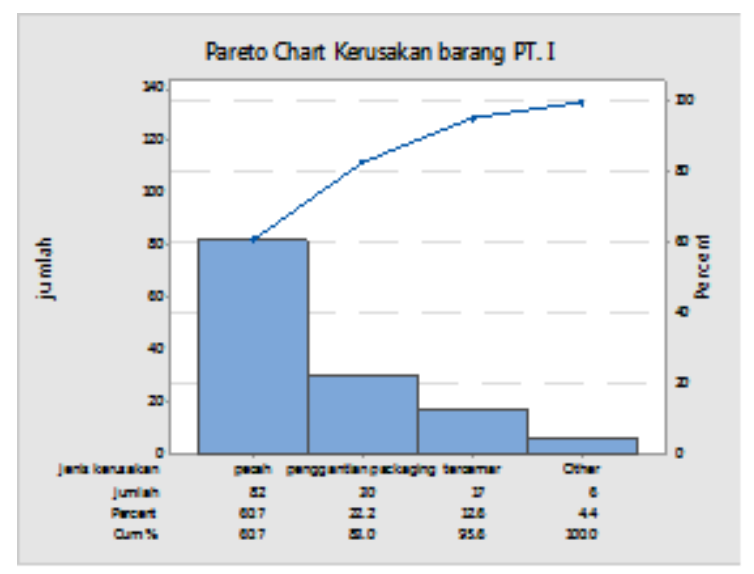

Sumber: Data olahan 2018
Berdasarkan diagram pareto diatas diketahui bahwa penyebab terbesar dalam klaim barang PT. I selama Januari-Maret 2018 adalah kerusakan pecah dan penggantian packaging. Diketahui pada barang pecah biaya yang di keluarkan untuk klaim selama Januari-Maret 2018 adalah Rp 17.042.400,- sedangkan untuk klaim penggantian packaging biaya klaim selama Januari-Maret 2018 sebesar Rp 274.000,-. Maka dari itu, fokus perbaikan untuk masalah klaim barang adalah pada klaim barang pecah pada barang obat dan alat kesehatan karena memiliki biaya klaim tertinggi.

\subsubsection{Tahap Analyze}

Tahap analyze merupakan tahap ketiga dalam metode DMAIC. Pada tahap ini dilakukan analisis data untuk mengidentifikasi masalah dan selanjutnya dapat dilakukan serangkaian pengembangan beberapa alternatif solusi perbaikan kualitas. Berdasarkan diagram pareto 4.4 pada tahap measure dapat ditentukan bahwa fokus perbaikan adalah barang pecah pada PT. I karena memiliki biaya klaim tertinggi dengan persentase $60,7 \%$. Setelah itu, maka dilakukan proses brainstorming dengan para pekerja bagian operasional. Proses brainstorming bertujuan untuk mengetahui penyebab jenis kerusakan yang terjadi berdasarkan pengalaman pekerja di 
lapangan. Hal ini dapat memudahkan penelusuran penyebab terjadinya jenis kerusakan tersebut.

Tabel 3.

Tabel Hasil Brainstorming Barang Pecah

\begin{tabular}{|c|l|}
\hline No. & \multicolumn{1}{|c|}{ hasil brainstorming } \\
\hline 1 & $\begin{array}{l}\text { Pekerja kurang memahami menangani } \\
\text { barang }\end{array}$ \\
\hline 2 & Bekerja secara terburuburu \\
\hline 3 & $\begin{array}{l}\text { Operator tidak memerhatikan lubang } \\
\text { pallet dan kondisi jalur yang akan } \\
\text { dilewati }\end{array}$ \\
\hline 4 & Tidak serius dalam bekerja \\
\hline 5 & Kekurangan pekerja shift pagi \\
\hline 6 & Bawa barang melebihi kapasitas \\
\hline 7 & Meletakkan barang sembarangan \\
\hline 8 & Pekerja sering menduduki barang \\
\hline 9 & Bekerja secara overtime \\
\hline 10 & $\begin{array}{l}\text { Barang berat disusun diatas barang yang } \\
\text { ringan }\end{array}$ \\
\hline 11 & Penyusunan kardus terbalik \\
\hline 12 & Penumpukkan barang melebihi kapasitas \\
\hline 13 & $\begin{array}{l}\text { Loading/unloading dilakukan secara } \\
\text { dilempar }\end{array}$ \\
\hline 14 & $\begin{array}{l}\text { Barang diletakkan di jalur aktif sehingga } \\
\text { tertabrak forklift }\end{array}$ \\
\hline 15 & 1 kardus tidak diisi full/eceran \\
\hline 16 & Isi barang tidak sesuai dengan BTTs \\
\hline 17 & $\begin{array}{l}\text { Barang mudah pecah tidak diberikan } \\
\text { packaging tambahan }\end{array}$ \\
\hline 18 & Kondisi gudang yang penuh oleh barang \\
\hline
\end{tabular}

Sumber: data olahan 2018

Berdasarkan tabel diatas diketahui terdapat 18 penyebab terjadinya barang pecah. Proses brainstorming ini dilakukan secara terpisah yaitu sesi pertama pekerja bongkar muat dan checker serta sesi kedua kepala divisi operasional dan sopir forklift. Hal ini dikarenakan waktu yang terbatas untuk melakukan brainstorming.

\section{Tahap Improve}

Tahap improve merupakan pengembangan solusi perbaikan atas akar masalah yang terjadi. Pada tahap ini dibuat ide-ide perbaikan proses kerja dari tahap analyze yaitu pada faktor materials dan methods. Berikut adalah solusi perbaikannya.

1. Membuat instruksi kerja mengenai penyusunan dan penanganan barang saat proses loading dan proses unloadling. Instruksi kerja ini akan disosialisasikan dan dijelaskan ke seluruh pekerja bagian operasional yang terkait pada proses di dalam gudang diantaranya sopir forklift, bongkar muat dan checker. Selain disosialisasikan instruksi kerja ini pun ditempel di ruangan bagian operasional dan area gudang yang dapat dilihat oleh seluruh pekerja bagian operasional. Instruksi kerja ini berfungsi sebagai acuan pekerja operasional pada proses unloading hingga proses loading barang sehingga ketika pekerja tidak tahu cara menangani barang pekerja dapat membaca instruksi kerja tersebut. Berikut 
adalah tabel instruksi barang pada proses loading dan proses unloading barang.

2. Menambahkan kolom informasi isi barang pada purchase order. Customer seperti PT. I yang tidak memiliki system khusus untuk pemesanan truk PT. Dakota Logistik Indonesia mengirimkan purchase order berbentuk data excel melalui e-mail. Pada purchase order yang dikirimkan oleh customer ditambahkan satu kolom konten berisi jenis barang yang di kirimkan. Hal ini bertujuan agar customer dapat mencantumkan informasi isi barang yang dikirim tanpa menghabiskan waktu banyak dan meminimalisir customer tidak mengisi informasi isi barang yang dikirim. Berikut adalah contoh purchase order dengan tambahan kolom informasi isi barang.

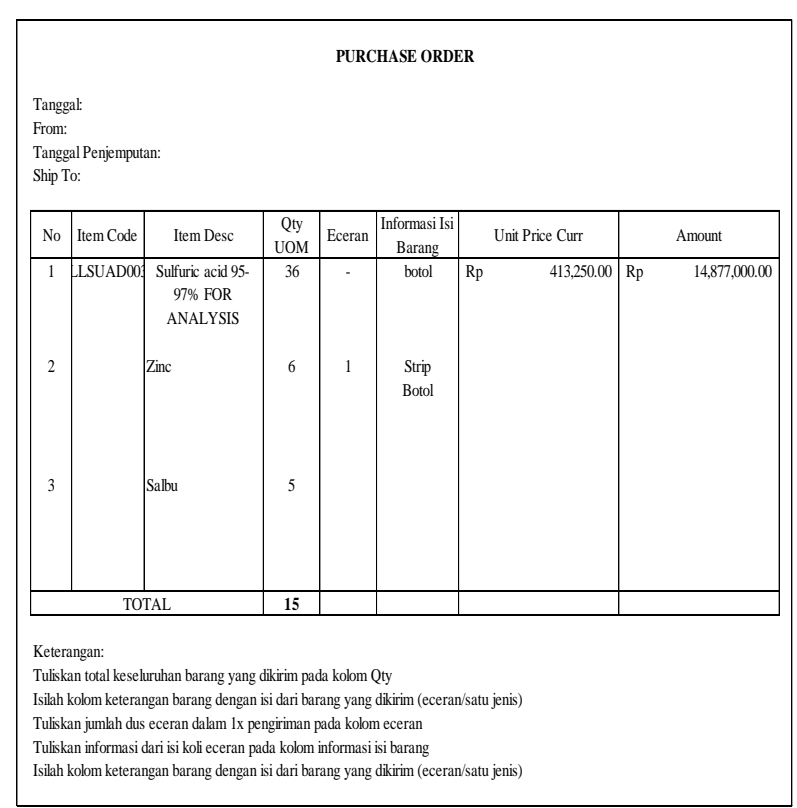

Sumber: data olahan 2018

Gambar 3.

Gambar Usulan Tambahan Kolom Pada Purchase Order

\section{Tahap Control}

Tahap control dibuat alat untuk memonitoring proses perbaikan apabila perusahaan akan mengimplementasikan usulan perbaikan pada tahap improve. Maksud dari monitoring adalah mengawasi dan mengontrol tahap improve untuk mengetahui dan menganalisis pengaruh usulan tersebut terhadap jenis kerusakan pecah barang obat dan alat kesehatan PT. I. selain itu, alat ini dapat digunakan sebagai evaluasi perusahaan terhadap usulan perbaikan tersebut. Berikut adalah rancangan alat untuk me-monitoring proses perbaikan.

1. Membuat checksheet dengan jenis kerusakan pecah pada perusahaan PT. I untuk barang obat dan alat kesehatan pada proses di dalam gudang PT. Dakota Logistik Indonesia. Checksheet ini digunakan untuk me-monitoring proses di dalam gudang pada saat perusahaan mengimplementasikan instruksi kerja yang telah dibuat pada tahap improve. Selain itu, dengan menggunakan checksheet dapat menjadi bahan evaluasi perusahaan pada akhir periode mengenai tingkat kerusakan barang pecah apakah terjadi penurunan atau kenaikan kerusakan barang setelah dilakukan implementasi usulan perbaikan pada tahap improve. 
2. Membuat checksheet berdasarkan purchase order yang PT. I kirim. Checksheet ini digunakan untuk memonitoring kegunaan tambahan kolom informasi isi barang pada purchase order customer yang telah dirancang pada tahap improve. Selain itu, dengan menggunakan checksheet dapat menjadi bahan evaluasi perusahaan pada akhir periode mengenai keefektifan penggunaan kolom tambahan informasi isi barang tersebut dengan kerusakan barangnya. Dapat dibandingkan dari total kerusakan barang saat customer mengisi kolom informasi isi barang dengan yang tidak diisi.

\section{SIMPULAN}

Berdasarkan permasalahan yang terjadi maka dapat disimpulkan bahwa Proses pergudangan di PT. Dakota Logistik Indonesia meliputi unloading barang dari truk, penyimpanan barang ke area gudang, hingga loading barang ke truk. Kerusakan yang menyebabkan biaya klaim terbesar adalah kerusakan barang pecah PT. I dengan biaya klaim sebesar Rp. 17.042.400,- serta persentase kerusakan sebesar $60,7 \%$. Usulan perbaikan pada tahap improve yang dapat dilakukan oleh perusahaan adalah membuat instruksi kerja pada proses loading dan unloading serta penambahan kolom informasi isi barang pada purchase order customer.

\section{DAFTAR PUSTAKA}

Fatimah, Fajar Nuraini D. 2016. Pedoman Praktis Menyusun STANDARD OPERATING PROCEDURE.

Yogyakarta: QUADRANT.

Gaspersz. (2007). Total Quality Management. Jakarta: PT. Gramedia Pustaka.

Herjanto, E. (2008). Manajemen Operasi. Jakarta: PT. Gramedia.

Poerwanto, G Hendra. (2012). Manajemen Kualitas.

https://sites.google.com/site/kelolakualit as. Diakses pada tanggal 15 September 2018.

Prasetyo, Hanung Nindito. (2016). Perbedaan Prosedur dan Instruksi Kerja. https://hanungnp.staff.telkomuniversity. ac.id/. Diakses pada 16 September 2018.

Prawirosentono, S. (2007). Manajemen Operasi Analisis dan Studi Kasus. Jakarta: Bumi Aksara.

Primanintyo, B., Syafei, M. Y., \& Luviyanti, D. (2013). Analisis Penurunan Jumlah Defect Dalam Proses Tire-Curing 
Dengan Penerapan Konsep Six Sigma. Jurnal Industri, 1-16.

Siregar, M. T., \& Puar, Z. M. (2018). IMPLEMENTASI LEAN

DISTRIBUTION UNTUK

MENGURANGI LEAD TIME PENGIRIMAN PADA SISTEM DISTRIBUSI

EKSPOR. Jurnal

Teknologi, 10(1), 1-8..

Siregar, M. T. (2015). IMPLEMENTASI DMAIC SIX SIGMA UNTUK PENINGKATAN KETEPATAN WAKTU PELAYANAN JASA PEST CONTROL MELALUI LEAN SERVICE. Manajemen Industri \& Perdagangan, 17(1).Triono, R. A. (2012). Pengambilan Keputusan Manajerial. Jakarta: Salemba Empat.

Warman, J. (2010). Manajemen Pergudangan. Jakarta: PT. Pustaka Sinar Harapan.

Wignjosoebroto, Sritomo. (2006). Pengantar Teknik dan Manajemen Industri. Surabaya: Guna Widya.

Yamit, Z. (2013). Manajemen Kualitas Produk dan Jasa Cetakan Keenam. Yogyakarta: Ekonisia.

Yunarto, H., \& Santika, M. (2005). Business Concept Implementation Series In
Inventory Management. Yunarto, H., \& Santika, M. 2005. Business Concept Implementation Series in Inventory MM. industrial engineering journal Vol 5., 8-20.

Yuri, T. Dan Rahmat Nurcahyo. 2013. TQM Manajemen Kualitas Total dalam Perspektif Teknik Industri. Jakarta: Indeks.

Zaroni. (2017). Logistics and Supply Chain Konsep dasar Logistik KontemporerPraktik Terbaik. Jakarta: Prasetiya Mulya Publishing. 